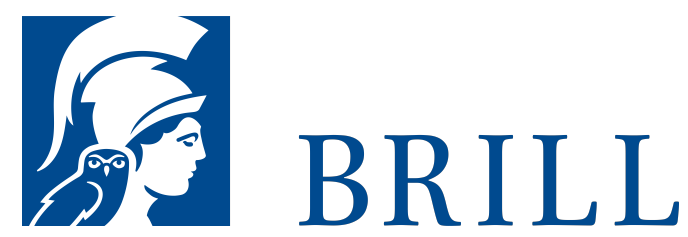

\title{
Wilhelm Flitner - Gesammelte Schriften
}

Erinnerungen 1889-1945

Author: Wilhelm Flitner

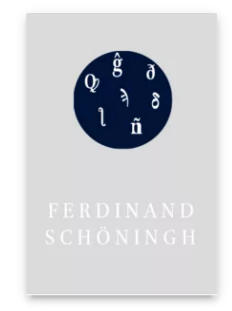

Published: o6

Feb 1987

Pages: 416

Seiten

Subjects:

Modern History,

History

Publisher: Brill |

Schöningh

Series:

Wilhelm Flitner, Gesammelte Schriften,

Volume: 11

Paperback

ISBN: $978-3^{-}$

506-72571-4

Price:

[US. \$ \$131.00 
Please send your order to: Brockhaus/Commission Tel: +49(o)71 541327 9216 | E-Mail: brill@ $\underline{\text { brocom.de }}$

For questions please contact: Brill Deutschland GmbH

Wollmarktstraße 115 | 33098 Paderborn | Germany

Tel: +49 (o)5251 69975 o | E-Mail: sales@brill.com. 